\title{
Developing the simulation model towards sustainability of implementing performance- based contract
}

\author{
I Putu Artama Wiguna ${ }^{1,}{ }^{*}$, Nadjadji Anwar ${ }^{1}$, and Hanie Teki Tjendani ${ }^{1}$ \\ ${ }^{1}$ Department of Civil Engineering, Institut Teknologi Sepuluh Nopember, Surabaya, Indonesia
}

\begin{abstract}
Performance-based contracts (PBC), one kind of the delivery system has been conducted in Indonesia starting in 2011. The aim of the implementation of $\mathrm{PBC}$ in Indonesia is to solve the premature deterioration of national roads in Indonesia that still occur to date and to achieve the best level of service. Implementation of performance-based contracts is not as easy as imagine since many contractors still don't understand to control the risk if they are given work with performance-based contracts. In this study used the system dynamic approach, the choice of this method because PBC is a long-term contract, where past events can affect current and future events, as well as future events, can be avoided by evaluating today's events and events in the past. In this paper will show the interface generated after the base model Stock Flow Diagram (SFD) is verified. After the model has been validated, the model is ready as a simulation tool to get the best performance-based contracting mechanism and implementation in Indonesia. So, it can be used in developing countries.
\end{abstract}

\section{Introduction}

A national road project with performance-based contracts has been conducted in Indonesia starting in 2011. The implementation of PBC in Indonesia aims to solve the premature deterioration of national roads in Indonesia that still occur to date and to achieve the best level of service. One of the pilot projects that is the case study in this research simulation is the Semarang-Bawen project. The project has a length of $22 \mathrm{~km}$. On a performance-based contract, the work is divided into several phases in the contract i.e. 1) planning and construction period 840 days, 2) maintenance service period 1643 days, and 3) maintenance period 180 days. In the planning and construction period, there is a normalization condition for 151 days at the beginning of the period [1].

However, in reality implementation of performance-based contracts is not as easy as imagine, since many contractors still don't understand to control the risk if they are given work with performance-based contracts because there are several factors that are difficult to avoid i.e. overloading, soil, and groundwater conditions as well as coordination among stakeholders related to the work on the road [2].

\footnotetext{
*Corresponding author: artama.wiguna@gmail.com
} 
In the implementation of performance-based contracts, it is necessary to take into recommendation some parameters that become benchmarks of the success of PBC. In this study the parameters used are road conditions, contractors profits and government benefits, so that the goal of PBC can be achieved that is the risk-sharing between the government and the third most able to endure the risk or contractors. One of the two sides should not be a loser but a "win-win solution" [3].

\section{Research methodology}

In this study used the dynamic system approach, the choice of this method because PBC is a long-term contract, where past events can affect current and future events, as well as future events, can be avoided by evaluating today's events and events in the past. When the events are described, it will be a closed loop [4].

The dynamic system consists of CLD and SFD. Causal loop diagrams are used to get the connexion between variables. Each connexion is illustrated with arrows marked as positive $(+)$ if the variables are each other reinforcing or as negative (-) if the variables are opposite. Stock and flow diagrams are composed of a few sections to facilitate the construction of the system that will be modeled [5]

In this paper will not show CLD and SFD since have discussed in other papers. But will show the interface generated after the SFD model is verified. The interface formed a PBC scheme simulator, in which there is controlled input and uncontrolled input. The controlled input of government is cumulative equivalent single axle load (CESAL) value and controlled input by the contractor is the speed of construction. While uncontrolled input is a rise in traffic and rainfall. The output of this simulation is contractor profit and government benefit.

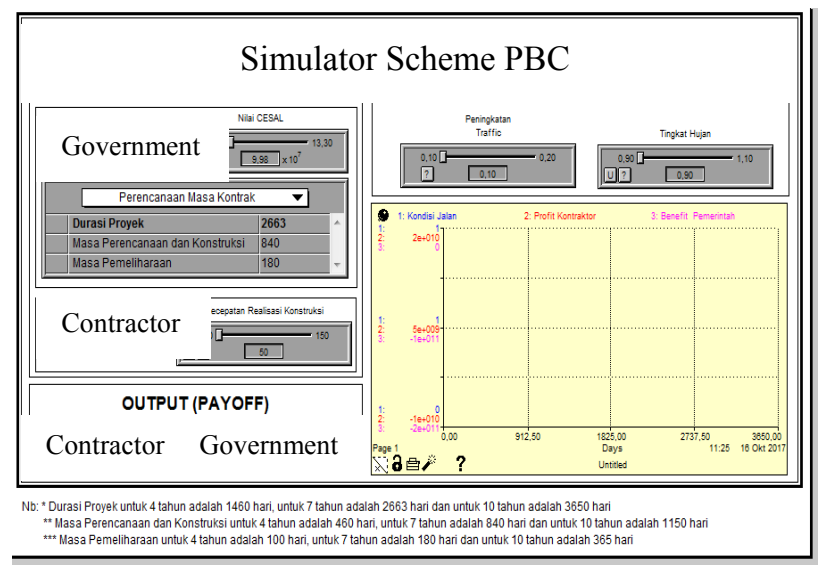

Fig. 1. Simulator scheme PBC.

In this paper, a causal loop diagram (CLD) is formed based on the risk factors that have been obtained from previous articles in the pre-bidding, bidding, design, construction, operation/ maintenance stages [6], and based on real conditions in the field on the Semarang road. Bawen who uses performance-based contracts. This CLD is a causal diagram with closed circles where the variables involved influence each other on road damage problems. Stock Flow Diagram (SFD) is a diagram of stock in and out which shows the variables that cause road damage and also variables that reduce road damage, and this diagram is quantitative because there is a formula to solve problems in the form of models. This model, before the simulation was conducted to find the "best practice" of the $\mathrm{PBC}$ implementation, was carried out a verification and validation process. 


\section{Results and discussion}

After inputting the formulas in the stock flow diagram (SFD) on the dynamic system obtained base model as shown below. So it can be done model validation. In the validation is known some validation of the structure (test of model structure), validation of character (test of model behavior). Validation character can also be divided into 2 (two) ways namely extreme conditions test and parameter test. If the base model has passed the verification and validation tests, then the model can be used as needed. Verification consists of verification of equality and dimensional consistency tests, all of which can be done in the software used. While the validation of the model is done by structure validation and character validation, where the model is declared valid if the simulation is done, the results will match or approach the actual condition.

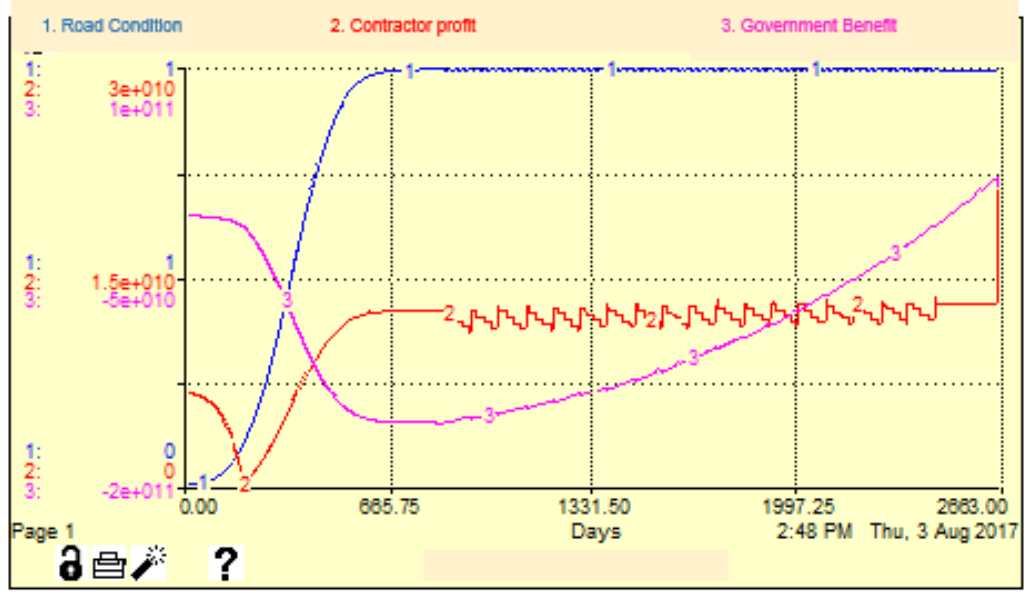

Fig. 2. Base Model PBC.

\subsection{Structural validation}

Structural validation aims to see the compatibility between model structure and system structure in the real situation [4]. In Semarang-Bawen KBK scheme system there are 3 phases, namely construction \& planning phase, construction implementation, and maintenance service period.

Structures in the planning phase of construction and construction implementation are as follows: a) The path condition (Fig. 2 number 1. blue), increases following the s-curve from a $0 \%$ progress state to $100 \%$. The construction planning phase and construction phase run simultaneously with duration of 840 days. b) The contractor's profits (number 2. red), at the beginning of this phase the contractor, receives an advance of $20 \%$ of the first year's indicative ceiling (about 6 billion rupiahs). The contractor's profit graph decreased at the start of the phase because the government disbursed the funds according to the number of completed jobs and at the beginning of the contractor's progress phase slowly following the nature of the projected curve. At the time of construction began fast (37\% point), profit contractor also began to increase again. c) Government Benefit (3. purple color), in this phase the road cannot be used and the government only spend funds for the process of road construction, then there is no benefit (only cost) that can be issued by the government until the day to 840 .

The structure in the maintenance service phase lasts from day 841 to day-to-day The condition of the road is almost always in $100 \%$ condition and can be used because of the 
rules in the contract that is "the road must be in international roughness index's (IRI) condition $<=4$ ". a) Contractor's profit decreased monthly due to road maintenance service but will increase every three months due to government road maintenance fund (as per contract rules), b) Benefit of government, in this phase the road can be used, so the government has received benefits.

Structure in the maintenance phase: a) Road conditions are always good where the contractor only conducts monitoring of road conditions. b) The profits of the contractor, no longer (or very little) cost and also do not get funds from the government. However, on the last day of this phase, the contractor receives retention of $5 \%$ of the total contract value (so $100 \%$ paid off). c) The benefit of the government, because road still can be used, then the government always get the benefit at this time. Because the model already represents the system following the real situation, then we can say that the model has passed the validation structure.

\subsection{Character validation}

Validation of character to see changes in the nature of the model will an event be similar to the real condition if the same event occurs. There are two ways to perform properties validation i.e. extreme conditions test and parameter test [4].

\subsubsection{Extreme condition}

Extreme Condition Test is to see the character of the system under extreme conditions. Variable changed from very low value to very high to see the nature of the system. Fig. 3 shows very low rainfall rate (decrease $30 \%$ ). The contractor's profit in the maintenance service phase has increased, because low rainfall causes a low level of road damage; therefore the cost of road repairs that contractors need to issue is also low.

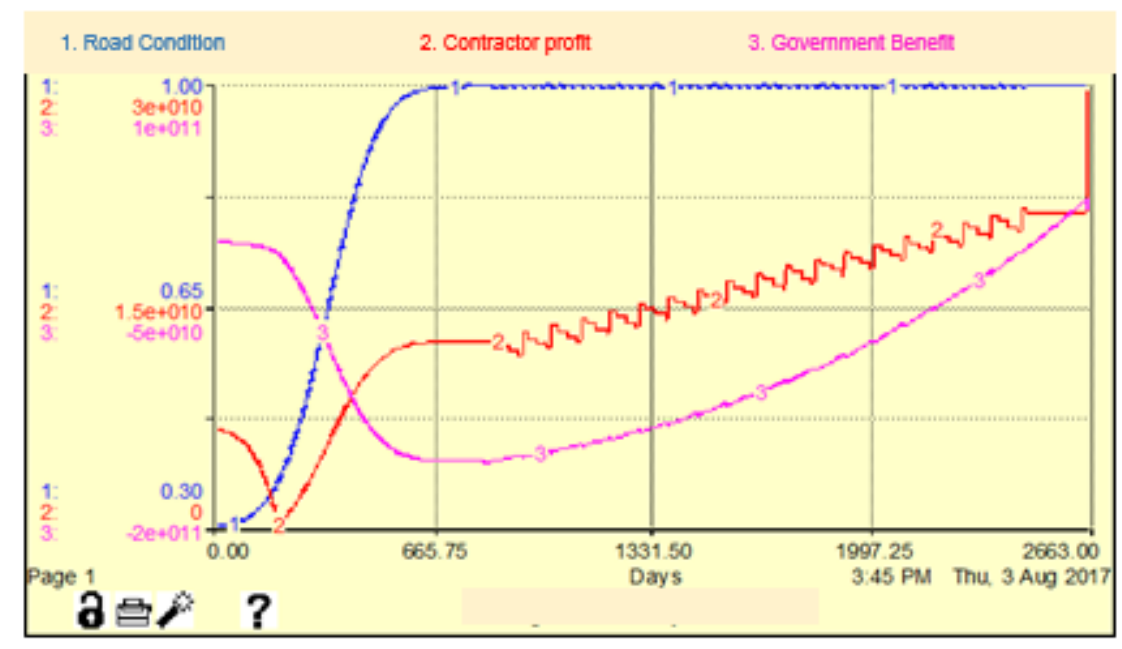

Fig. 3. Very Low Rainfall Rate (-30\%).

The profit of the contractor in the maintenance service phase has decreased because high rainfall causes a high level of road damage. Therefore the cost of road repairs that need to be issued by the contractor is also high. Fig. 4 shows very high rainfall rate up to $30 \%$. 


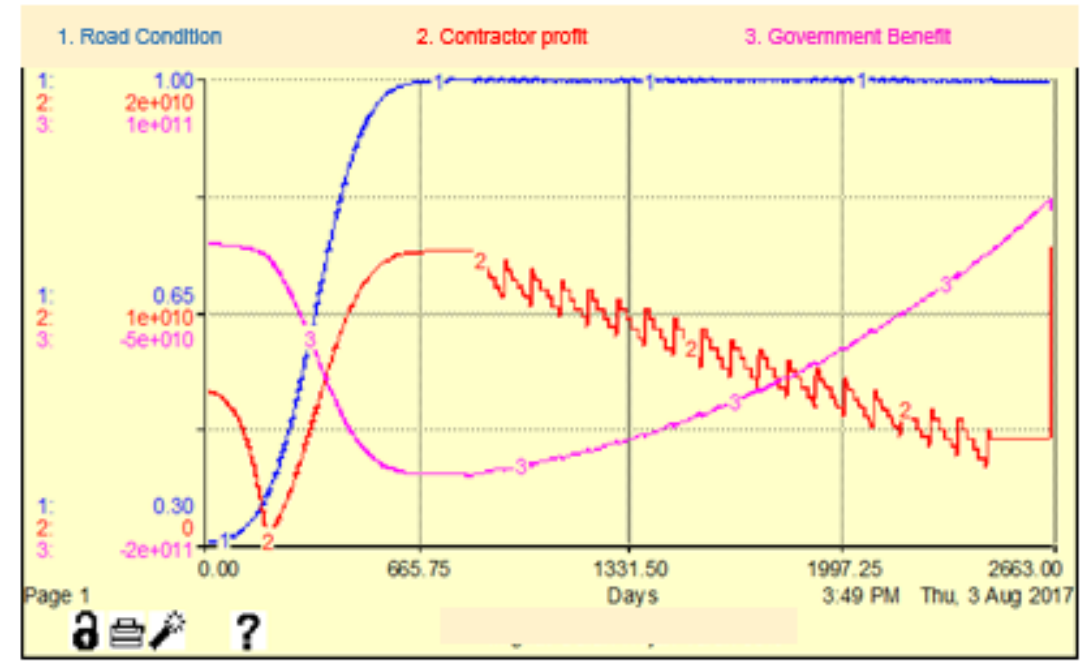

Fig. 4. Very high rainfall rate $(+30 \%)$.

Fig. 5 shows traffic increase variable (no improvement). There is not much change in the contractor's profit because in the initial state (10\% increase in traffic) and the no increase in traffic condition does not exceed the specified CESAL value and no overloading occurs. However, what has changed is the value of government benefits decreased, because the number of vehicles on the road a little, then the government benefits in building this road is also reduced.

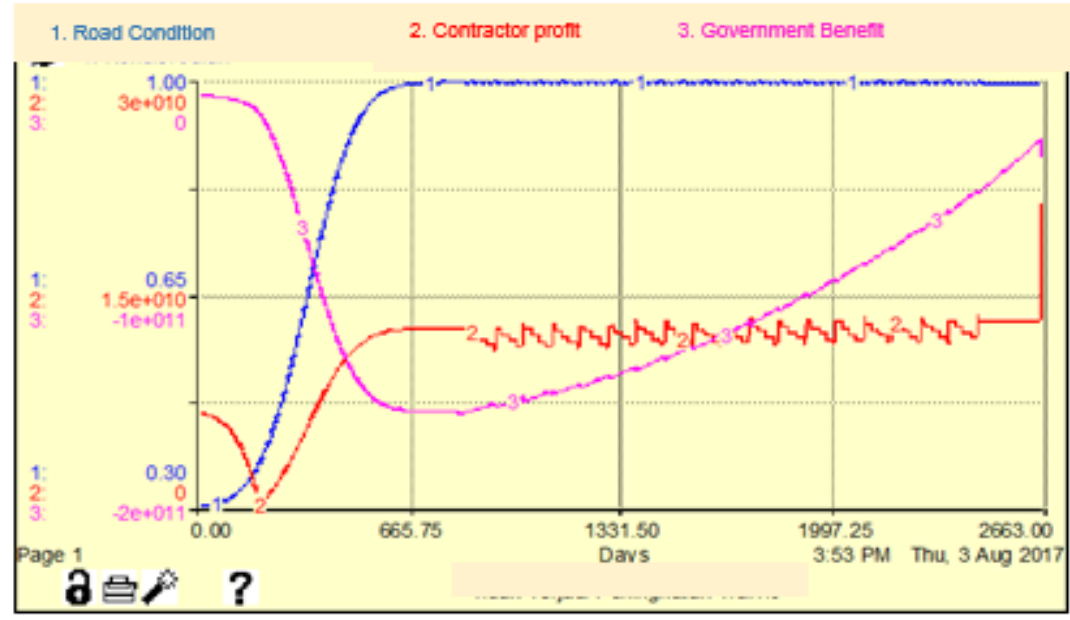

Fig. 5. Traffic increase variable $(0 \%)$.

Fig. 6 shows the traffic increase variable (up to 50\%). In this condition, an overloading condition occurs where the amount of traffic exceeds the CESAL value of the plan. The government will provide compensation to contractors in case of overloading, therefore on the contractor's profit graph does not decrease because the government will pay compensation according to the value of overloading that occurred. On the other hand, government benefits have increased as the number of vehicles using roads has also increased. 


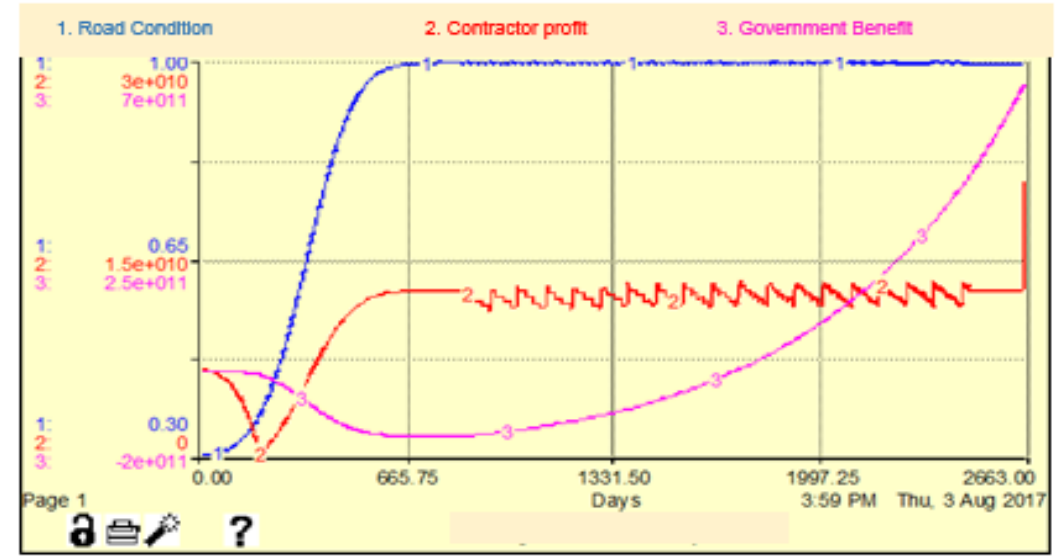

Fig. 6. Traffic increase variable $(50 \%)$.

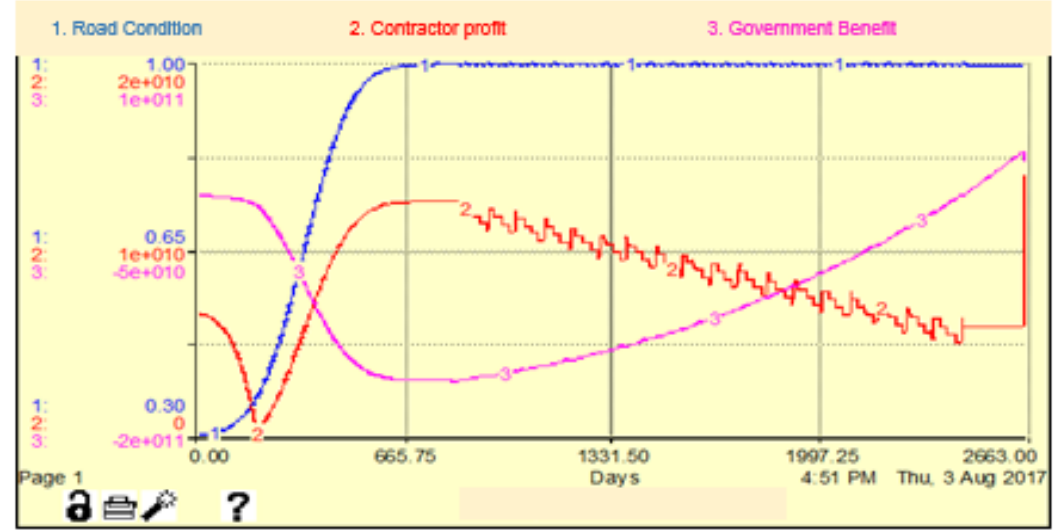

Fig. 7. Determination of low CESAL Value $(59,000,000$ traffic).

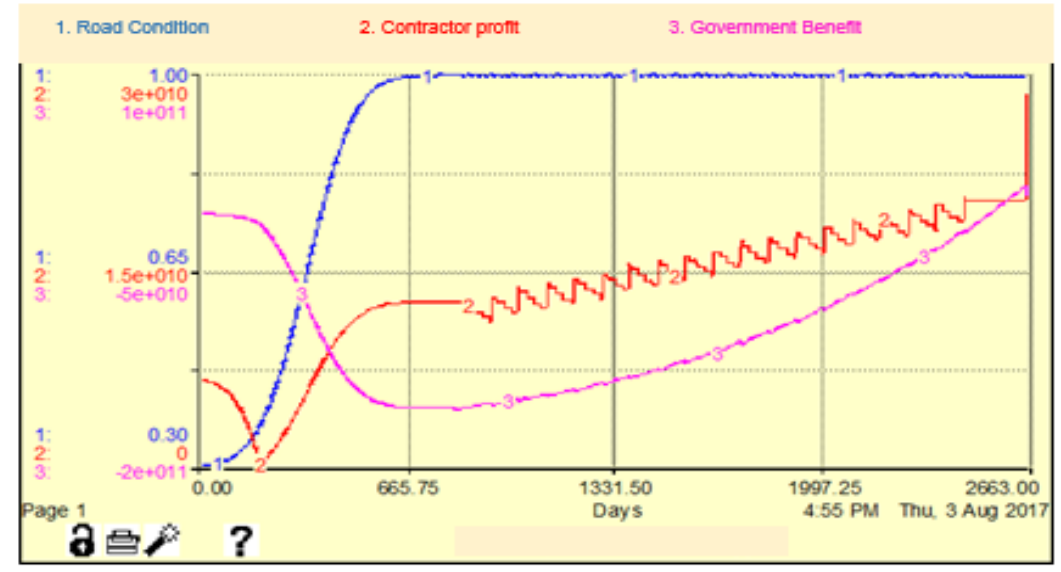

Fig.8. High CESAL value determination (99,000,000 traffic).

Fig. 7 shows determination of low CESAL value $(59,000,000$ traffic). A low CESAL value setting causes the government budget for the maintenance service phase to decline as well. This results in contractor profits also declining. The government's benefits and road 
conditions have not changed significantly. Fig. 8 shows High CESAL value determination $(99,000,000$ traffic). High CESAL value assignment causes the government budget for the maintenance service phase to increase. This results in contractor profits also rising. The government's benefits and road conditions have not changed significantly.

\subsubsection{Parameter test model}

Parameter test model aims to see the nature of the effect of changing a variable to another variable. To see this trait, we again take the graph from the construction speed decrease (as much as 50\%) in Fig. 9 and the construction speed increase (as much as 50\%) in Fig. 10.

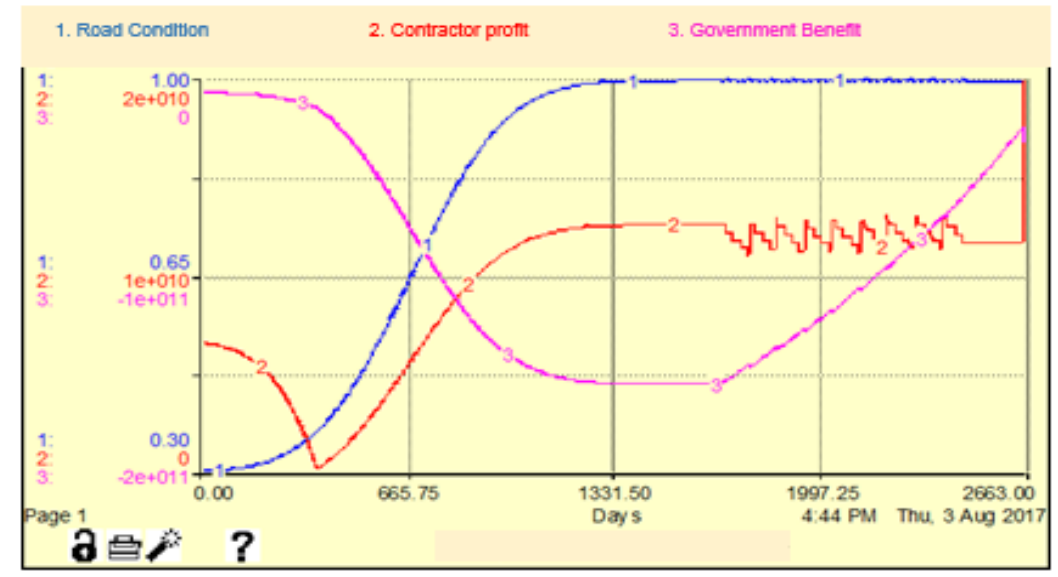

Fig.9. Construction speed $-50 \%$.

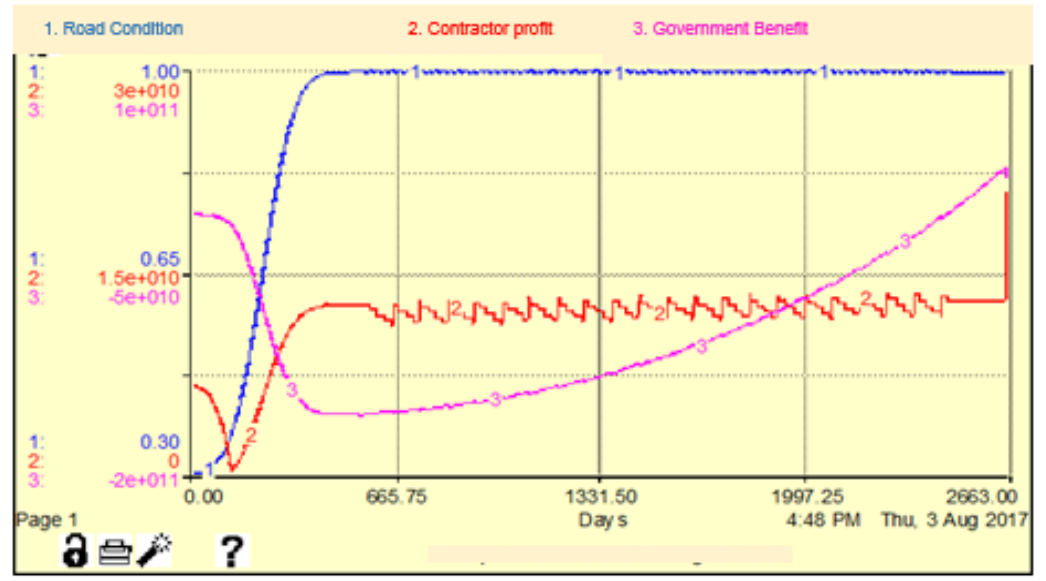

Fig.10. Construction speed $+50 \%$.

Construction speed decreased by $50 \%$ resulting in the late completion of road construction. This led to the delayed completion of the road that should have been completed by day 840 to be completed by the $1600^{\text {th }}$ day. The contractor's profits also increased more slowly and the maintenance service time was also shortened. The government benefit decreased significantly because the time in the old maintenance and construction phase caused a very short time for users to use the road. 
Construction speed increased by $50 \%$ causing the completion of planning and construction phases to be faster (should be on day 840 to 550 days). The contractor's profits also increase faster, and the phase of maintenance services is even faster. Government benefits also increase significantly due to the availability of longer roads for road users. Therefore, the model already represents the nature of the system in extreme conditions and relationships between variables that match the real state, then we can say the model has passed the validation properties.

\section{Conclusions}

In the ongoing research, implementation of performance-based contracts in Indonesia can be done following natural conditions, increased traffic, road user characteristics and work relationships between government and contractors. After the model has been validated, the model is ready as a simulation tool to get each payoff the government and the contractor. The next research to get the best practice of performance-based contracting mechanism and implementation in Indonesia.

We greatly appreciated the Indonesian Ministry of Research Technology and Higher Education for providing the grant fund for this research.

\section{References}

1. Dirjen Bina Marga, Kontrak Berbasis Kinerja Semarang-Bawen (2011)

2. R.Z. Tamin, A.Z. Tamin, P.F. Marzuki, 2011. Procedia Eng. (2011)

3. H.T. Tjendani, N. Anwar, I.P.A. Wiguna. Eng. Journal (2017)

4. Sterman, Business dynamics: system thinking and medelling for a complex world. (McGraw-Hill, Chicago, 2000)

5. S.O. Ogunlana, H. Li, F.A. Sukhera, J. of Cons. Eng. and Man. 129, 5 (2003)

6. I.P.A Wiguna, N. Anwar, H.T. Tjendani, Prosiding Simposium II -UNIID (2017) 